\title{
Abstract Knowledge, Embodied Experience: Towards a Literary Fieldwork in the Humanities
}

\author{
Nobonita Rakshit ${ }^{1} \&$ Rashmi Gaur ${ }^{2}$ \\ ${ }^{1}$ Doctoral Student, Department of Humanities \& Social Sciences, Indian Institute of Technology \\ Roorkee, Roorkee, India. nrakshit@hs.iitr.ac.in, https://orcid.org/0000-0002-8584-862X \\ ${ }^{2}$ Professor, Department of Humanities \& Social Sciences, Indian Institute of Technology Roorkee, \\ Roorkee, India, rashmi.gaur@hs.iitr.ac.in
}

\begin{abstract}
The paper attempts to read the representation and (re)creation of Sundarbans into the narrative structure of the three works of Amitav Ghosh- The Hungry Tide (2004), Gun Island (2019), and Jungle Nama: A Story of the Sundarban (2021) through the idea of 'literary fieldwork' that the paper develops by putting these literary narratives in conversation with the fieldwork narratives. Drawing from Puri and Castillo's (2016) concept of "humanities fieldwork" and Ghosh's (2016) idea of sensuous recognition and identifying the literary texts as primary data for fieldwork, the paper brings home a new reading practice which here qualifies not only the role of Ghosh, the literary ethnographer but also the natives of Sundarbans who narrate their own testimonies of the place and their politics of survival. Their embodied experiences of Sundarbans are embedded with the author's literary experiments in the texts to advance the place of fieldwork in literary studies and redefine the ideas of fieldwork in the humanities in general. In other words, the paper dwells upon the author's creative response in portraying the difference between the abstract knowledge of the Sundarbans and the embodied experience of the place that offers literary fieldwork within which it accommodates the points of view of the author, the natives, and the readers and thus, changes the conventional practices of perceiving fieldwork in humanities.
\end{abstract}

Keywords: Sundarbans, literary fieldwork, humanities fieldwork, sensuous recognition, literary ethnography.

\section{Literary Fieldwork: An Introduction}

Munizha Ahmed (1999), in the remarkable work "Notes on Fieldwork," witnesses "less clearly defined" roles and methodologies of fieldwork in the literary sphere than the disciplines like anthropology or history and postulates that the expansion of literary studies and its "growing emphasis on interdisciplinary perspectives" would be benefitted if more attention can be given on the literary fieldwork (as cited in Puri and Castillo, 2016, p. 4). This aspect of critical literary practice, even in this era of digital humanities, has put us into a place where the "ink-tinted gloves, quality cameras, and pens and notebooks" continue to exist as the "instruments of literary criticism" (Seguín, 2014, p. 10). In this broad context, the present paper shall look into the 
representation and (re)creation of Sundarbans into the narrative structure of the three works of Ghosh- The Hungry Tide (2004), Gun Island (2019), and Jungle Nama: A Story of the Sundarban (2021) through the idea of 'literary fieldwork' that the present paper develops by putting the literary narratives in conversation with the fieldwork narratives.

This intrusion of fieldwork in literary criticism is one such instance where the known fieldwork-centric paraphernalia is renovated to form compatibility between "the knowledge that we gain through place-based research" and "the conventions of scholarship in which we are professionalized" (Puri \& Castillo, 2016, p. 2). This fieldwork in literary studies demands attention because of its renovated academic responses and its scrutiny of literary texts vis-à-vis the lived experiences. The bounded texts are meticulously reanimated by the unbounded and unfinishedness of lived experiences through the conjecture of literary text, subjective experiences, the lens of the local, and field exposure inherent in the literary fieldwork that the paper shall throw light upon. Unlike anthropology or history that also "offer a capacious archive on...[local]...cultures and a great self-reflexivity about fieldwork" (Puri \& Castillo, 2016, p. 7), literary texts manifest a gripping dynamic of the very act of the human mind merging the experiences of a local place, its geographical consciousness, its cultural practices, etc., without any particular methodology in order to create a narrative that is both imaginative and embodied (Mendelson, 1999). This "sensory and affective turn" (Pandian, 2015, p. 16) or the very act of writing that involves the field experience as well as the creative response of the author is something that makes possible the literary fieldwork in Amitav Ghosh's The Hungry Tide (2004), Gun Island (2019), and Jungle Nama (2021) which the present paper shall dwell upon. Identifying the literary texts as primary data for fieldwork and drawing from Puri and Castillo's (2016) concept of "humanities fieldwork" and Ghosh's (2016) idea of sensuous recognition, the present paper brings home a new reading practice which here qualifies not only the role of Ghosh, the literary ethnographer but also the natives of Sundarbans who narrate their own testimonies of the place and their politics of survival. Their embodied experiences of the Sundarbans are embedded with the author's literary experiments in the texts to advance the place of fieldwork in literary studies and redefine the ideas of fieldwork in the humanities in general. Further, the paper dwells upon the author's creative response in portraying the difference in the abstract knowledge of Sundarbans and the embodied experience of the place that offers literary fieldwork within which it accommodates the points of view of the author, the natives, and the readers. It thus changes the conventional practices of perceiving fieldwork in humanities.

\section{Understanding Fieldwork in the Humanities: Representing Abstract Knowledge and Embodied Experience}

Before we move forward with the argument on determining the representational differences in abstract knowledge and embodied experiences of the Sundarbans through the texts of Ghosh, we must delve deep into the necessity of developing the idea of fieldwork in literature or humanities in general. Puri and Castillo (2016) examine the ever-growing "skepticism, caution, discouragement and deferral" in undertaking fieldwork as a mode of study among scholars in "literary studies specifically or in the humanities generally" (p. 2). Keeping in mind the handful numbers of fieldwork-based humanities or literary studies which are "often located at the fringes 
of disciplines, or dispersed across the muddled undisciplines that may be highly praised but somewhat institutionally homeless," Puri and Castillo "articulate, share, and refine our [conventional] practices;...compare our verifying understandings of fieldwork in our different disciplines, most of which have no public discourse on fieldwork and offer no training in how to conduct it" (pp. 2-3). Asking questions such "what happens to literary studies when it shifts the medium of its encounter with difference from text to everyday life, or more precisely when it doubles the textual encounter with lived encounter?", "How does that movement between bounded text and the unbounded, unfinishedness of life matter?", they forge the concept of "humanities fieldwork" that "shift[s] the humanities' medium of encounter" (p. 5). They forge this concept in the context of the "global south" to check and counter the "material inequalities and epistemic privileging of western/northern and elite southern norms" (p. 6). Unlike the conventional fieldwork-based research, they refrain the concept of "humanities fieldwork" from becoming a standardized perspective and argue:

Fieldwork is not the only route to knowledge. ...but fieldwork offers different archives, different media of encounter, different methods of engagement, different interlocutors and thus different insights - that can deepen our understanding of others in a way that also involves an estrangement and reassessment of the self. (p. 17)

As the paper would argue, this innovative approach is the effect of rejecting any self-evident, recognizable, or pre-existing model or genre for theorizing fieldwork in humanities. They further redefine the term "theorizing" by moving beyond the "thick description or distilled detail that literary scholars so value in literature" and by assimilating it with "fieldwork" that allow a "necessary capaciousness and openness of experience, a recognition of an at least temporarily undisciplined engagement with place" (p. 11). In the present context, where we intend to read Sundarbans' representations and (re)creations through the literary texts and reveal the fieldwork adopted by the author, the concept of fieldwork is redefined to a great extent. The creative vision of Ghosh, which is a confluence of his journalistic investigation, ethnographic approach, and artistic insights, adopts this technique of fieldwork and further redefines it through his sensuous recognition to forge a new reading process which we will now discuss.

Drawing on the lack of literary representation of the issues of climate change and global warming in modern realist fictions as improbable and irrational, Ghosh envisions a new reading practice that will be able "to look into the world better than the predecessors," "to transcend the isolation in which humanity is trapped," "to rediscover the kinship with other beings," and will generate "a transformed and renewed art and literature" (Ghosh, 2016, p. 217) in his book The Great Derangement (2016). Breaking free from the mainstream categorization of modern realist fiction as serious and science fiction, Ghosh seeks a more flexible yet probing approach to fabricate the new reading practice in literary studies. An ardent researcher in anthropology with the experiences of a journalist, Ghosh attempts to conceive the approach of fieldwork as a culmination of the process of recognition through a dialogue between the past and present and the literary texts and lived experiences of the natives. Ghosh seeks to fuse the recognition of the past with the present and literary texts with the lived experiences of the natives to achieve a sense effected recognition. To Ghosh, recognition is a movement from "ignorance to knowledge" (p. 6). Ghosh explores how the affective impact of witnessing the unprecedented natural forces and its deleterious consequences across the world ecology become a mobilizing force in discovering an 
undiscovered vein between abstract knowledge of these forces, provided by the over-reliance on Scientific data and the in-field experiences of the natives. Developing around this very act of witnessing, the mode of sense effected recognition seeks to inculcate an inclusive understanding where the natives' knowledge of the irrational and improbable forces co-exists with the objective empirical observation. Therefore, it can be argued that the fusion of the text with the lived experiences effects a sensuous recognition where the "humanities fieldwork" (Puri\& Castillo, 2016, p. 6) brings out the documented and erased histories of past events, the embodied experience of the natives, the vernacular sense of place, the regional literature, and the oral folklores to formulate the reading practice envisioned by Ghosh. As in this context, the idea of Ghosh has been telescoped with the concept of Puri and Castillo in the paper, advancing the place of fieldwork-based literary studies in the literature. The "sensory and affective turn" of the literary fieldwork is the "chance to confront and engage the open-ended, unfinished nature of life, to follow thing as they happen, to fold the uncertainty and vulnerability of living relations into the very substance of our intellectual work" (Pandian, 2015, p. 280). Ghosh's artistic insights meet with his ethnographic knowledge in The Great Derangement (2016), evoking an awareness of partiality, providing knowledge of implied and glimpsed realities, highlighting the involved labors and lenses, and recognizing the similarities and differences in theorizing the literary fieldwork. With this approach of literary fieldwork, the paper will now explore how the abstract knowledge and embodied experience effects the narrative of Sundarbans, a locale where the sensuous recognition initiates a dialogue between the author, the readers, and the characters, which finally provides a vernacular intervention into the mainstream literature's medium of encounter.

The literary fieldwork in Ghosh's narratives is crucial for understanding the difference in the abstract knowledge of Sundarbans and the embodied experience of Sundarbans in the present texts. Fieldworks, which are generally understood as important tools in humanities to dialogue with a wide range of local people rather than experts to make the readers understand the local issues, and local cultural experiences, are understood here as an indispensable literary tool. This is so because, as argued by Puri and Castillo (2016), the nature of the fieldworks is so enriching that it provides "richness of ongoing relationships forged in the field, the possibility of collaborative work, invigoration of the felt connection of academia with the world outside it, a sense of our writing as one large shared project, and intense pleasure at the conjunction of sensory and intellectual cognition" (p. 2). Such fieldwork provides the platform where the cognition of the author in perceiving the Sundarbans becomes instrumental in the articulation of the representational differences of Sundarbans through the literary texts and fieldwork narratives as the author, though does not have the lived experiences of the natives, has the experimental vision of a literary artist and fieldwork experience of the place. Unlike the mainstream literature and literary criticism as a discipline and a practice respectively that have no tradition of dialogue with non-experts and ordinary people in the course of everyday life, in fieldwork-based literary texts like the present ones in question, the tone is conversational where the role of the author is both a literary scholar and an ethnographer. This is so because the author's creative license complements the objective observations of the lone ethnographer model. However, it has to be noted that the creative response of the author is not limited to the ecologically aware postcolonial texts. It is through the fieldworks that are built not simply upon the subjective experience of the author but upon the narrations of lived experiences of natives either through the natives 
themselves or through the characters of texts, that the literary ethnographer, Ghosh in the present case, represents rather (re)creates the Sundarbans. His endeavors to perceive the local lives, cultural practices, regional literature, etc., affect the conventional reading process. Therefore, his artistic dimension is built upon the subjective experience and the native's narration of everyday lives that help him consolidate the resources. However, as the paper shall attempt to decode, Ghosh's fieldwork is not a mere collection of information for resource consolidation but a subjective intervention into the everyday lives of the people of Sundarbans and its recreation in his fiction and non-fictional works. In his Berlin lecture series (2016), Ghosh describes his field visits, extensive conversations with the natives of Sundarbans and the people who have migrated from here to New York, Venice, etc., a study of the local myths and oral folktales, all of which he finally forges into his last four works extensively.

\section{Reading Sundarbans: Locating Fieldwork narratives in Literary Texts}

On the south of Eastern Indian state of West Bengal, the Ganga, Brahmaputra, and Meghna rivers with their innumerous tributaries create a vast delta, namely Sundarbans, before plunging into the great Bay of Bengal. Spreading over ten thousand square kilometers in India and Bangladesh and comprising thousands of habitable and inhabitable islands, this delta is "one of those areas of the world where the lie of the land mocks the absurdity of international treaties because it is virtually impossible to enforce border laws on a territory that constantly shifts, submerges and resurfaces with the ebb and flow of the tide" (Mukherjee, 2010, p. 108). A UNESCO World Heritage site comprising four protected areas under reserve forest and wildlife sanctuary, this delta is named after the Mangrove trees, locally known as Sundori trees. In his latest Story of the Sundarban, Ghosh writes:

Thousands of islands rise from the rivers' rich silts, crowned with forests of mangrove, rising on stilts.

This is the Sundarban, where great rivers give birth;

to a vast jungle that joins Ocean and Earth. (2021)

However, apart from these sensuous details, this "forest of beauty" (Mukherjee, 2010, p. 108) is also marked with climatological catastrophes like cyclones, flash floods, sea-level rise, extreme poverty, illegal migration, climate migrants, and government negligence. Representing this 'other side' of Sundarbans, Annu Jalais, a fieldwork-based researcher in her essay "Dwelling on Morichjhanpi: When Tigers Became 'Citizens', Refugees 'Tiger-Food'" (2015), writes:

The Sundarbans region is also referred to as 'Kolkata's servant' ('Kolkatar jhi'), due to the large number of people from this region working as servants in the houses of Kolkata's affluent. Before the introduction of shrimp seed collection in the 1980s the islanders had barely enough to eat. For many islanders, especially those who owned no land, working in the forest was the only way of making a living. (p. 1760)

These alternative narratives of the Sundarbans have been largely unexplored through the lens of the daily lives of ordinary people, the socio-political issues of the place, and the eco-social injustices. For representing the Sundarbans and later re-creating it in his literary works, Ghosh 
visits the island towns of the Sundarbans several times, spends time there, keeps notes on the dynamic landscapes, participates in the local cultural practices, reads the regional pre-modern literature extensively, and finally, publishes his works in 2004, 2019, and 2021, the locales of which are the Sundarbans. The recalled perception of the hardships of life and the Sundarbans' recurrent presence in their narratives help the readers relive the place, which is further filtered through the humanistic lens of the author. Thus, it can be argued that the texts are not simply portrayals of the author's imagination but root their cognitive stimuli in a sense effected recognition and is inherently fieldwork-based projects in spirit. This fieldwork is further realized through the texture of the characters in his literary texts. We as readers are continuously made aware throughout the texts about the presence of Ghosh in the narrative mapping, and we further realize that the events are not simply placed in the literary texts but are crafted out of the personal experiences of the author. The literary fieldwork situates the readers amid the crisis of the place and enables them to take part in the text, making the fieldwork possible.

The representation of the Sundarbans in The Hungry Tide, Gun Island, and Jungle Nama provides a particular narrative structure that sufficiently challenges the idea of the Sundarbans as a vast wilderness, nights in decorated boats-cum-hotels, watching the Royal Bengal Tiger, a carpet of soft foliage, etc. as has been presented in mainstream literature and popular culture. These images are ruling and, at times, the most recognizable models for the literary scholarship that, in turn, fuels the ecotourism strategy. Ghosh, in The Great Derangement (2016), in a path-breaking way, pen-portrays the Sundarbans as "nothing like the forests that usually figure in literature":

The greenery is dense, tangled and low; the canopy is not above but around you, constantly clawing at your skin and your clothes. No breeze can enter the thickets of this forest; when the air stirs at all it is because of the buzzing of flies and other insects. Underfoot...there is a bank of slippery, knee-deep mud, perforated by the sharp points that protrude from mangrove roots.

$[\ldots]$

In the Sundarbans, tigers are everywhere and nowhere....If it charged, you would not see it till the last minute, and even if you did, you would not be able to get away; the mud would immobilize you. (p. 37)

This suggests that the conventional and abstract descriptions of the Sundarbans are the emblem of "privileged separation" of the knowledge or the researcher from the "messy thing we called everyday life" (Puri \& Castillo, 2016, p. 12). Everyday life cannot be separated from the place in Ghosh as the sense of the place is inseparably merged with the lived experiences of the local communities. However, the indistinguishability between the literary text and the lived experiences does not suggest the fabrication of modified truths to consolidate the fieldwork. Instead, it signifies the fluidity of the two. This fluidity draws the imagination of the readers to the narrative space and guides it to the Sundarbans, effecting a social, political, cultural, and ecological understanding of place in crisis. This fluidity creates an open space where the literature and literary studies begin a dialogue with the literary experts, non-experts, and a wide range of people, producing a fieldwork-based project that archives different real-lived experiences, mediums of encounter, multiple methods of engagement, discreet interlocutors, and different insights. 
Ghosh's two novels, The Hungry Tide and Gun Island and the graphic verse Jungle Nama, are the outcome of the fieldwork-based project, in which he documents the narratives of the Sundarbans and the experiences of the natives and outsiders and further, weaves his collected information of the place with the collective memories of the people. While all these three works revolve around the present-day Sundarbans and its fragile ecosystem, they also trace the histories of colonial invasion, the exploitations of the local communities and the animals, the unempirical insertion of modernization practices, the climatological calamities, and the social changes that have deleterious impacts on the interrelationship of the people and the place. While talking about the memories of the place and his repetitive returning to Sundarbans, Ghosh postulates, "An uncle of mine was a schoolteacher in the Sundarban, so we used to visit him there when I was a child. My memories of those visits led me to write The Hungry Tide, and I suppose they are largely responsible for bringing me back there again and again" (Modi, 2021). The novel The Hungry Tide is a story of the protagonist, the Sundarbans, and its ravaging by the Morichjhanpi Massacre, the destruction of its ecosystem, its non-human witness to the struggle of the inhabitants, the regenerative spirit of the landscapes, its oral documentation through the local myths of Bon Bibi and local cultural practices like Jatra, oral recitation, songs, etc. and finally its all-encompassing presence in the lives of the characters like Nirmal, a school teacher in the Sundarbans, Fokir, a local boatman, Piya, a Seattle-based cetologist and Kanai, a Delhi-based translator. Published after seventeen years in 2019, Gun Island represents the two time-frame through the story of Sundarbans in the present day and Sundarbans in the seventeenth century. In the present time frame, the Sundarbans is connected to Venice and New York through the peripheral ecological crisis in the forms of sea-level rise, whale breaching, forest fire, etc., that are no longer limited to the Sundarbans only. The seventeenth-century time frame is introduced to remind the environmental calamities and the Little Ice Age that disrupted the islands and made them uninhabitable once for the Gun Merchant and now for its inhabitants. Through the myth of the Bandoogi Sadagar, modeled upon the myth of Manasa Mangal Kavya, a 17th-century text of Bengali Literature, the novel connects the Sundarbans with Venice, where the whole force of working-class people are ecological migrants from Sundarbans, India, and Madaripur, Bangladesh. Published in 2021, Jungle Nama: $A$ Story of the Sundarban is a graphic verse adaptation of the myth of Bon Bibi, Shah Jongoli, and Dokkhin Rai, an oral story of Sundarbans, the world's largest mangrove forest. The graphic verse, a confluence of the image and text, captures the journey of Dukhey, a poor boy who becomes a victim of the greedy Dhona, a merchant, his encounter with the tiger Dokkhin Rai and finally his rescue by Bon Bibi and Shah Jongoli, the goddess of the forest and her warrior brother. While talking about the genesis of the text Jungle Nama, Ghosh postulates, "In January 2000, I accompanied Annu [Jalais] and a group of villagers from the Sundarban, on a trip to a remote island for a Bon Bibi puja. We went in rowboats, and the puja was performed on a mudbank where a tiger's fresh pugmarks could be seen. It was an amazing experience. You could say that was when the story of Jungle Nama began" (Modi, 2021). According to Ghosh (2021), the local cultural practices and belief systems teach the "ideas of limiting greed, and of preserving a balance between the needs of humans and those of other beings," generating the "essential values for this era of planetary crisis." All these three texts capture the rapidly changing eco-social conditions of the Sundarbans amid the ecological and historical catastrophes that question the established practices of representing the Sundarbans. The fieldwork taken by Ghosh physically and through the literary texts represents and (re)creates 
the Sundarbans in more authentic, immediate, and at once, experimental ways. This is so because the fieldwork and experience are inseparable where experience, as Pandian (2015) contends, is not only a matter of legitimacy, immediacy, or absence of reflections, but also "a matter of experiments with life, an arena of conjectures, trials, and different lessons" (p. 293). Ghosh does not merely travel to the Sundarbans or remain an objective observer during the cultural practices. Rather, the freshness of his representations and (re)creations lies in the considerations - of the socio-ecological crisis of the place and presenting them in the genre that suits the crisis; reflections - of the struggles, anxieties, and uncertainties of the local communities; analysis-of the cultural practices and indigenous epistemologies; and trying - to relocate the difference in abstract knowledge and the embodied experience of the place.

As the embodied experience and the catastrophe-ravaged place lack the literary documentation, Ghosh re-constructs the details of Sundarbans right after the ecological and historical catastrophes from the memories and myths of his oral as well as expert narrators, which find the documentation in his literary texts under the fieldwork-based project of mapping Sundarbans. The texts are the detailed narrative map of the Sundarbans from the 17th century onwards. The novels meticulously posit characters like Nirmal, Piya, Fakir, and Kanai in The Hungry Tide and Rafi, Tipu, Dinu, and Piya in Gun Island. They associate their belongingness to the Sundarbans through remembering the place, the fragile ecosystem, and the local epistemologies and cultural practices around which the everyday lives of the ordinary people revolve. Even more broadly, the myth of Bon Bibi and Bandoogi Sadagar, their enactments through Jatra and engravings on the temple wall, the repeated recurring of cyclones like Aila and their long-lasting consequences on daily lives - all these become entry-point into the realm of Sundarbans which provide altogether different perspectives of the "forest of beauty" (Mukherjee, 2010, p. 108). The novel Gun Island (2019) mentions the severe poverty and mass migrations caused by the repeated recurring of catastrophes:

Hundreds of miles of embankment had been swept away and the sea had invaded places where it had never entered before; vast tracts of once fertile land had been swamped by salt water, rendering them uncultivable for a generation, if not forever.

The Sundarbans had always attracted traffickers, because of its poverty, but never in such numbers as after Aila; they had descended in swarms, spiriting women off to distant brothels and transporting able-bodied men to work sites in faraway cities or even abroad. [...]

Sometimes, said Moyna, it seemed as though both land and water were turning against those who lived in the Sundarbans. (pp. 48-49)

Creating a narrative mapping of the Sundarbans and mapping these narratives through the intuitive reading and fieldwork narrative makes the fieldwork a part of the literary-critical practice and a medium of encounter.

\section{Conclusion}

The paper thus attempts to explore the crucial role of fieldwork in literary studies and the creative vision of Ghosh in representing and (re)creating the Sundarbans through the confluence of literary 
texts and the fieldwork narratives. Unlike an anthropologist or a geographer, who provides a close but objective representation of a place, Ghosh, the literary ethnographer, merges the disciplinary boundaries and forges a narrative mapping of the Sundarbans through literary fieldwork. The paper reads the literary fieldwork as a source of experiential and experimental knowledge production where the undocumented narratives of local place, culture, and ordinary people are considered and dealt with utmost care to recognize the alternate knowledge of the interrelationship of people and the place. As the literary text and the lived experiences of the natives are the crucial vehicles to represent and (re)create the place, the interrelationship of people and the place becomes an embodied relationship that lacks objectivity, abstract knowledge of the place, and impersonality of representation. This is what Ghosh accomplishes through his literary practice. His narrative capacity holds the personal narratives, anthropological readings, and empirical data away to keep on the novelistic pleasure and never eliminated them while expressing his concerns about the Sundarbans generated from these pieces of information. These data collected through fieldwork vivify his representation and (re)creation of the Sundarbans in the textual space of his literary works. In other words, together, the fieldwork narratives and the literary narratives produce a new practice of literary studies that attempts to overcome the marginality of fieldwork in literary studies or humanities in general and put it into practice in academia.

\section{References}

Ghosh, A. (2004). The Hungry Tide. Penguin Books India.

Ghosh, A. (2019). Gun Island. Penguin Random House.

Ghosh, A. (2021) Jungle Nama: A Story of the Sundarban. Fourth Estate India.

Ghosh, A. (2016). The Great Derangement: Climate Change and the Unthinkable. Penguin.

Jalais, A. (2005). Dwelling on Morichjhanpi: When Tigers Became 'Citizens', Refugees 'Tiger-Food'. Economic and Political Weekly, 40(17), 1757-1762. http://www.jstor.org/stable/4416535

Mendelson, Donna. (1999). "Transparent Overlay Maps": Layers of Place Knowledge in Human Geography and Ecocriticism. Interdisciplinary Literary Studies, $1(1)$, 81-96. https://www.jstor.org/stable/41201145

Modi, C. G. (2021, May 28). Interview: Amitav Ghosh, Author, Jungle NAMA: A Story of the Sundarban. Hindustan Times. https://www.hindustantimes.com/books/interviewamitav-ghosh-author-junglenama-a-story-of-the-sundarban-101622214985175.html

Mukherjee, U. (2010). Postcolonial environments: Nature, culture and the contemporary Indian novel in English. Springer.

Pandian, A. (2015). Ree/ World: An Anthropology of Creation. Duke University Press.

Puri, S., \& Castillo, D. A. (Eds.). (2016). Theorizing Fieldwork in the Humanities: Methods, Reflections, and Approaches to the Global South. Springer.

Seguín, B. (2014). The Texture of Literary Fieldwork. LASA Forum, 45(2), 9-10. https://forum.lasaweb.org/files/vol45-issue2/OnTheProfession4.pdf 
Nobonita Rakshit is a Doctoral student in the Department of Humanities and Social Sciences at the Indian Institute of Technology Roorkee, India. Her research interests include postcolonial studies, environmental humanities, disaster narratives, and South Asian literature.

Rashmi Gaur is a Professor of English in the Department of Humanities and Social Sciences at the Indian Institute of Technology Roorkee, India. Her research interests include Professional Communication, Culture and Gender Studies, Media studies, Digital Humanities, Modern Fiction, and Indian Writing. 